\title{
Coulisses
}

Revue de théâtre

14 | Printemps 1996

Varia

\section{Une Noce, d'Anton Tchekhov}

\section{François Bugaud}

\section{OpenEdition}

\section{Journals}

Édition électronique

URL : http://journals.openedition.org/coulisses/4542

DOI : $10.4000 /$ coulisses.4542

ISSN : 2546-9460

\section{Éditeur}

Presses universitaires de Franche-Comté

\section{Édition imprimée}

Date de publication : 1 mai 1996

Pagination : 33-34

ISSN : 1150-594X

\section{Référence électronique}

Francois Bugaud, «Une Noce, d'Anton Tchekhov », Coulisses [En ligne], 14 | Printemps 1996, mis en ligne le 20 mars 2019, consulté le 25 octobre 2019. URL : http://journals.openedition.org/coulisses/ 4542 ; DOI : 10.4000/coulisses. 4542

Ce document a été généré automatiquement le 25 octobre 2019

Coulisses 


\title{
Une Noce, d'Anton Tchekhov
}

\author{
François Bugaud
}

1 Tchekhov, fils d'épicier dans une bourgade, élève médiocre, vécut intensément mais peu. Il meurt à quarante-quatre ans. Médecin, écrivain, dès son jeune âge il fut non le fils original et inutile d'une bonne famille aisée, cultivée mais son unique soutien.

Nous n'en dirons pas plus. Chez nous, nous aimons les légendes respectables. Tchekhov sera donc le médecin qui écrit comme Victor Hugo sera grand-père pour des générations d'élèves. Et pour achever le maquillage, Tchekhov sera mélancolique. Les mises en scène seront donc de subtiles fleurs fanées comme ces décors surannés de vieilles familles et de celles qui en rêvent.

Tout ceci n'est-il pas original et de bon goût? C'est là appauvrir et réduire très singulièrement cet écrivain extrêmement composite, doué d'un appétit féroce. Le pire n'étant jamais loin, Tchekhov, sous une trame bonasse, quasi banale, un tantinet languissante, tisse une architecture vigoureuse, très élaborée, au rythme allègre, disloqué, avec ses coups de foudre, ses brisures, ses ralentendo comme ses molto vivace. Nous sommes loin d'un Tchekhov uniquement délicat! Ses constructions dramatiques pour le moins fulgurantes annoncent, dirait-on, les événements cahotiques de ce début de siècle, plus encore en grand précurseur qu'il est, un langage post-classique en rupture avec une figuration lisse, homogène, linéaire comme une physique classique déterministe: "La science traditionnelle identifiait raison et certitude, ignorance et probabilité. Il n'en est plus ainsi aujourd'hui », nous dit Ilya Prigogine, prix Nobel de chimie. ${ }^{1}$

2 Une Noce de Tchekhov, c'est un regard cru sur la noce de modestes employés qui s'échinent à faire grand. Le trait est rapide, direct. Dès les premiers mots, sans plus de préambule, éclatent les premiers conflits :

3 " Non, non et non ». La noce sera ainsi de bout en bout. La mariée est inexistante. Ses chairs sont avant tout de la dot, des titres, un placement: beau bétail. Le fascisme rappelle des faits extrêmes, on oublie qu'il fait son lit dans le bon gros sens partagé communément. Tchekhov le fait éclater ici par tous les pores de sa pièce et de ses créatures jetées dans cette pochade drolatique pour en cacher l'amertume, la violence inouïe... Que l'on songe aux dialogues gendre/belle-mère, Yat et le beau-père, 
gendre / Yat, le beau-père avec l'immigré du moment : grec en ce temps-là. Qu'est-ce qu'il peut bien y avoir en Grèce ? Dans ces pays du Sud, il n'y a rien bien sûr. Il faut tout leur apprendre. Tchekhov est trop malin cependant pour sombrer dans la caricature qu'un jeu de comédiens peut à son insu privilégier. Comme dans la commedia dell'arte il faut tenir les deux bouts: folle gaieté et délicatesse des sentiments, burlesque et raffinement, là est la difficulté. Tchekhov ne sombre pas non plus dans le discours, la pièce à thèse qui plaît tellement aux Français cartésiens. Cela dédouane de tout. Tchekhov, de la vie composite, bizarre, étonnante, prend tout. Comme dans la Grèce de son invité, confiseur et pâtissier grec, il y a dans ses pièces de tout. Point d'allégeance au beau langage de cour, ni à des protecteurs, ni à des éditeurs, ni à une caste de lettrés ${ }^{2}$. Tchekhov voit. Médecin, il voit de tout, fils d'épicier, il n'omet rien, ne gomme rien, même lorsqu'il deviendra célèbre et bénéficiera d'un certain confort matériel : "Nous ne voyons pas, nous n'entendons pas ceux qui souffrent et tout ce qu'il y a d'effrayant dans la vie se déroule quelque part dans les coulisses. C'est une hypnose générale. En réalité, il n'y a pas de bonheur, il ne doit pas y en avoir ». Tchekhov ira au bagne de l'île Sakhalin. Il y reste trois mois. "J'ai tout vu, il n'y a pas à Sakhalin un seul forçat ou déporté à qui je n'aie parlé ». Voir : le regard brûlé de celui qui ne ferme pas les yeux quand ça l'arrange. Il n'est pas temps ici d'arranger les choses avec art pour se trémousser dans un salon de bonnes manières fût-ce avec des idées excitantes sur le bas peuple entre carrosse à grande vitesse et antichambre ministérielle, encore moins de pleurnicher avec une âme toute neuve de martyr à qui un petit prince aurait retiré un strapontin. Pudeur, pudeur, et gaieté, c'est la manière des poètes! Tchekhov ne pleurnichera donc pas. Tchekhov voit, veut voir. Là une cerisaie, ici une noce, une noce complètement ratée. Il bouscule les invités dans la folie de la fiction théâtrale. La pièce explose et chavire dans une tempête de fines observations navales, dans un rythme effréné avec un entêtement digne du poète bien décidé à nous embarquer ailleurs que dans les marchandages : "J'étouffe, ... j'étouffe, donnez-moi une tempête », dira Zmeïoukina, la sage-femme qui chante mais ne veut pas chanter.

Monter Une Noce c'est donc beaucoup moins monter un repas avec sa cohorte de lieux communs, que le spectacle en bistrots impose quelquefois (faut-il rappeler les contingences très fortes de tels lieux?), que de tenter de montrer derrière ces personnages esquissés d'une petite pièce de trente minutes, où la musique vient à son tour contrarier le cours de la façon la plus intempestive, cette fringale générale au sens propre et figuré.

... Bientôt le dégel ..., quel dégel! C'est une affaire de rythme avant d'aller au-delà dans le montage de ce dramascule. Des lignes mélodiques se superposent, se croisent, se heurtent: ce sont des forces doubles, dirait Antonin Artaud: violence et légèreté, énergie vitale et peur de vivre.

"Le secret des états d'âme tchekhoviens réside dans le rythme de sa langue ", dira Meyerhold ${ }^{3}$. Qu'importe la table, les couverts... écouter le rythme de sa langue ici traduite... le tenir de bout en bout afin que, mine de rien, le drame aille à son terme sans jamais faiblir ni se noyer en considérations subalternes, décoratives, pseudopsychologiques, tel fut notre souci à tous. Chacun, chacune, comprit vite que c'était là la seule façon de porter la truculence, la particularité de chaque personnage, et de soutenir ce climat ambigu et quasi clownesque, combien cruel, de gens qui s'oublient pour ainsi dire comme cela nous arrive, comme cela arrive à ces notables assez sottement dans leur habit de paon, sous nos yeux attristés, lucides et ravis devant tant 
de naïve suffisance. «Hum... et des directeurs généreux, vous en avez? (le beau-père au grec)

\section{Dessin de Nicolas Tchekhov in Réveil Matin}

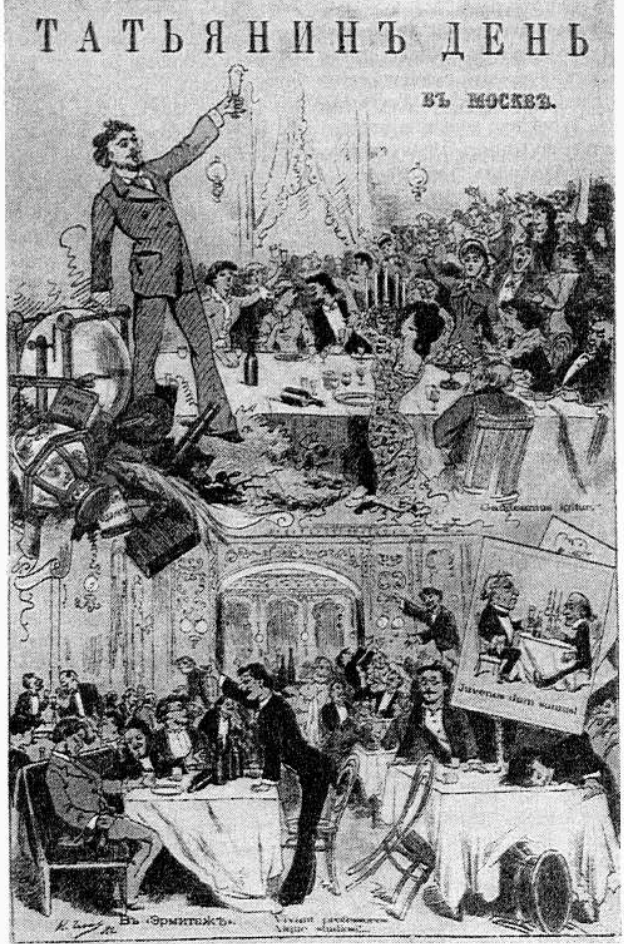

\section{NOTES}

1. in Résonance $n^{\circ}$ 9, 1995.

2. Cf. le beau texte de Jean Genêt sur Rembrandt, Parenté de poètes...

3. in Ecrits, Age d'Homme, Tome 1.

\section{AUTEURS}

FRANÇOIS BUGAUD

Né en 1947 en Bourgogne, exerce une activité d'artisan de théâtre écrivain et metteur en scène. Il vient de terminer une très conséquente recherche de DEA sur les enjeux du théâtre du XVI ${ }^{\mathrm{e}}$ siècle 
français (Paris III, 1995, Bibliothèque Armand Gatti et Bibliothèque Universitaire de FrancheComté). Il enseigne également au Conservatoire National de Région de Franche-Comté à Besançon depuis 1990. Avec quelques complices il fonde la compagnie Max-Théâtre en 1996. 